\title{
EEN BUITENGEWOON SURINAAMS VERSLAG
}

\author{
DOOR
}

W. R. MENKMAN

Het Staatsdrukkerij- en Uitgeverijbedrijf te 's Gravenhage heeft in 1948 het verslag uitgegeven (Deel I Documentaire Inleiding) der Commissie tot bestudering van Staatkundige Hervormingen in Suriname, ingesteld in 1945, die tot taak had te onderzoeken welke wensen en verlangens onder de Surinaamse bevolking leven ten aanzien van de politieke structuur van het land, onder de in uitzicht gestelde nieuwe verhoudingen.

Er valt wel een merkwaardig verschil te constateren tussen Oost en West, in betrekking tot het vraagstuk der autonomie. Voor Indië beschikte men over de resultaten van een in December 1941 beëindigd onderzoek (rapport Visman), terwijl aan de West in December 1942 een nieuwe politieke status toegezegd werd en een kleine drie jaar later begonnen werd met te onderzoeken wat de ingezetenen eigenlijk verlangden.

Het hier behandelde eerste deel van het verslag der Surinaamse commissie bedoelt een indruk te geven van den toestand des lands, de kennis waarvan nodig geoordeeld werd voor de beoordeling der wenselijkheid van wijzigingen in het staatsbestel.

Begonnen wordt met een demografisch overzicht, dat interessant is omdat het meer recente gegevens bevat dan de tot en met 1948 verschenen Surinaamse Verslagen.

Zo wordt thans voor 1946 de totale sterkte der bevolking aangegeven als te hebben bedragen 177.880, plus 22.000 Bosnegers en 3.700 Indianen, de twee laatste cijfers natuurlijk geschat. Het inwonertal zou dus reeds enkele jaren geleden de 200.000 overschreden hebben.

Wij vinden vermeld, dat er in 1870 nog 29.548 geëmancipeerden onder staatstoezicht stonden; het Koloniaal Verslag over 1862 gaf aan, dat op 31 December van dat jaar 36.484 onvrijen aanwezig waren, dus zes maanden vóór de vrijverklaring. 
Cijfers betreffende den loop der bevolking tonen, dat na 1816, tot en met 1890, het zielental steeds afnam; daarna begon het accres, natuurlijk voor een goed deel dank zij de immigratie. Grote geboorte-overschotten echter vertonen zich sedert het begin der twintigste eeuw eveneens.

Van de_ 177.880 inwoners in 1946 bestond nog maar 44.34\% uit z.g. Creolen; de Aziaten waren (Bosnegers en Indianen buiten beschouwing gelaten) in de meerderheid. Van de Creolen wonen er ongeveer tweemaal zoveel in de stad Paramaribo als in de districten; van de Brits Indiërs intussen zijn er toch ook bijna 20\% stadsbewoners.

Dat tussen 1900 en 1946 het percentage Christenen geregeld afgenomen is, tegenover Hindoes en Mohamedanen, ligt voor de hand; eerstgenoemden zijn sedert omstreeks 1940 in de minderheid, in 1946 was de verhouding ongeveer als $4: 5$.

De huwelijksstatistiek toont aan, dat van assimilatie tussen Aziaten niet-Aziaten nog zeer weinig sprake is; het aantal huwelijken per 1000, inwoners was sedert 1920 over het geheel achteruitgegaan.

Op 1 Januari 1941 trad de wettelijke rəgeling in werking betreffende Aziatische huwelijken en gedurende 1941 en 1942 konden vóór 1 Jan. 1941 naar eigen ritus gesloten huwelijken alsnog als wettig ingeschreven worden. In de periode 1941-1946 werden in totaal tussen Aziaten gesloten 881 huwelijken volgens de algemene bepalingen van het B.W., tegenover 5693 volgens de bijzondere bepalingen. Bij dit laatste cijfer schijnen nog opgeteld te moeten worden 5463 in 1941 en 1942 gewettigde rituele huwelijken, vóór 1 Januari 1941 gesloten. Merkwaardig is, dat van de overgangsregeling vooral Brits Indiërs, van de definitieve vooral Javanen gebruik gemaakt hebben.

Verreweg de grote meerderheid der z.g. Brits Indiërs zijn Nederlandse onderdanen, als zijnde in Suriname geboren; slechts ongeveer 3000 leden dezer bevolkingsgroep immers golden nog als vreemdelinge $n$. Er wordt de aandacht gevestigd op den onbevredigenden status van Ned. onderdanen, die dus eigenlijk geen Nederlanders zijn; de wenselijkheid van het instellen van een Surinaams burgerschap wordt bepleit.

Het procentuele cijfer der levend geboren kinderen was in 1945 het hoogste voor de Br. Indiërs, dan volgden de Creolen. Ruim 47 per 1000 van de groep voor de eerstgenoemden, ruim $33 \%$ van de groep voor de laatsten zijn natuurlijk zeer gunstige cijfers. 
Ook de sterftecijfers maken een goed figuur, ruim 11 per 1000 inwoners in 1946, dat is even weinig als in 1920 in Nederland, waar echter sedert de sterfte nog afgenomen is.

Van het procent der buitenechtelijke geboorten wordt gezegd, dat het van 70.8 van het totaal in 1940 gedaald is tot 43.3 in 1945. In deze periode echter vielen de regelingen betreffende de Aziatische huwelijken; welken invloed deze regelingen gehad hebben, valt uit de gepubliceerde gegevens niet op te maken. Geklaagd wordt over het te geringe aantal erkenningen door de vaders, of door de beide ouders.

Wat de veranderingen van woonplaats betreft wordt er op gewezen, dat voor het stadsdistrict (Paramaribo) in 1945 een vestigingsoverschot te constateren viel van 2700 personen. Het zou wellicht interessant zijn te vernemen hoevele der nieuwe stedelingen Aziaten waren, want ook voor hen heeft Paramaribo aantrekkelijkheid. Intussen was het grote vestigingsoverschot van 1945 een uitzondering; het wordt niet nader verklaard.

Dat de toestand der financiën tijdens den oorlog aanmerkelijk verbeterd is, was voldoende bekend, hoewel de opbrengst der middelen na 1943 geregeld weder gedaald is.

Er worden beschouwingen gewijd aan het plan-Idenburg van 1907, in 1918 gewijzigd en feitelijk mislukt, al is men in de begrotingsboekhouding een splitsing der uitgaven blijven handhaven (thans Gewone Dienst, Buitengewone Dienst en Kapitaaldienst). Het denkbeeld, de uitgaven voor opbouw en ontwikkeling te bestrijden uit leningen, is nimmer verwezenlijkt kunnen worden, omdat het uitgeven van zodanige leningen mislukte, zodat de vereiste gelden, niet voor den gewonen bestuursdienst gevoteerd, als kasvoorschotten van het moederland verkregen moesten worden. Berekend wordt, dat in de veertigjarige periode 1907-1946 het streven om Suriname tot ontwikkeling te brengen rond honderd millioen gulden aan Nederland gekost had, aan subsidie, leningen en andere bijdragen. Ten slotte toch niet meer dan twee en een half millioen gulden per jaar en terecht wordt er op gewezen hoe onbelangrijk deze offers eigenlijk geweest zijn, in verhouding tot het geheel der rijksuitgaven.

Ook wordt er in het rapport nog eens d s nadruk op gelegd, dat de bestuurskosten van een land met een weinig talrijke bevolking uiteraard naar verhouding hoog zijn.

Gedurende den oorlog ingevoerde extra belastingen waren natuurlijk ten dele bestemd om weder ingetrokken te worden. Haven- en loodsdienst echter zullen permanent de inkomsten 
der openbare kas verhogen; Suriname heeft het voorbeeld van Curaçao gevolgd, door in den vorm van haven- en loodsgelden feitelijk belasting van de scheepvaart te heffen.

De economische opbloei van Suriname in de oorlogsjaren is niet in 1945 door een onmiddellijke inzinking gevolgd; van een direct intredende werkloosheid is weinig te bespeuren geweest. Gememoreerd wordt de belangstelling, in 1946 en 1947 door het buitenland getoond, voor het vestigen van industrieën in Suriname.

Van het onderwijs in Suriname wordt een historisch overzicht gegeven, dat aanvangt met de vestiging van het Nederlandse gezag in 1667 en de ontwikkeling schetst, vooral onder de thans nog van kracht zijnde regeling van 1876.

De kosten van het onderwijs per leerling worden gesteld op bijna $f 21 .-$ in 1900, bijna $f 65$. - in 1925 en $f 36.65$ in 1945. De in 1920 ingevoerde ,,gelijkstelling" deed de kosten enorm stijgen, wat aanleiding gaf tot een vereenvoudiging, t.w. het beperkt lager onderwijs in de districten. De subsidiëring van het bijzonder onderwijs, onder omstandigheden als de in Suriname bestaande, wordt voorgesteld als ten dele een verkapte steunverlening aan de kerstening der bewoners van het binnenland.

Het onderwijs, zoals het zich thans in Suriname aan het oog van den rapporteur voordoet, wordt door hem beoordeeld als vrijwel over de gehele linie verouderd en onvoldoende. Vooral wanneer bedacht wordt dat de Nederlandse taal en ook naar Nederlandse maatstaf goed onderwijs, van grote waarde geacht moeten worden, voor Suriname zelf en voor de Nederlandse cultuur.

De rapporteur over de volksgezondheid geeft interessante beschouwingen, ook ten aanzien van de te verwachten toekomstige samenstelling der bevolking. Uitgaande van den aanwas door geboortenoverschotten in de jaren 1938-1942 zou de gehele bevolking na ongeveer 44 jaar verdubbeld zijn; op dezelfde basis echter zou de Britsindische groep daarvoor slechts 31 jaar nodig hebben, de Javaanse 42 jaar, de Creoolse evenwel niet minder dan 67 jaar.

De zorg voor de volksgezondheid, zo wordt betoogd, mag zich niet bepalen tot individuele ziekenverpleging; het is van het grootste belang dat volks- en besmettelijke ziekten op grote schaal bestreden worden, waartoe tot dusver de materiële hulpmiddelen en de sterkte van het personeel onvoldoende waren. Natuurlijke bevolkingsaanwas is voor Suriname een groot voor- 
deel, doch alleen wanneer daarmede samengaat verhoging der arbeidskracht en dus van de productiviteit.

Die aanwas heeft sedert 1922 een groter aandeel gehad in de toeneming dan de toch zo belangrijke immigratie, waarbij dan bovendien nog bedacht moet worden, dat sedert 1938 geen massale immigratie meer plaatsgehad heeft en dat zelfs een 4000-tal Surinamers, meest jeugdige en geselecteerde individuen, uitgetrokken zijn naar de Ned. Antillen.

Er wordt gepleit voor een betere hygiënische en medische verzorging der woudbewoners (Bosnegers en Indianen), terwijl met betrekking tot de schoolvoeding gezegd wordt, dat slechts aan een betrekkelijk kleine groep ondervoede kinderen in de stad op school een karige maaltijd verstrekt wordt.

Van het hospitaal te Paramaribo wordt gemeld, dat het geheel vernieuwd stond te worden en, naar gehoopt werd, modern geoutilleerd. De aan dit hospitaal verbonden geneeskundige school heeft heel wat medici afgeleverd, niet alleen ten behoeve van de eigen bevolking; wij lezen dat bij den gezondheidsdienst in Suriname en op de Ned. Antillen vele Surinaamse medici in dienst waren, dat er meer dan 50 in Nederland werkten, in Indonesië wellicht evenveel.

Dat het aantal lepralijders in Suriname naar verhouding zo groot is wordt in verband gebracht met het feit, dat nergens de registratie dezer zieken zo deugdelijk is als hier.

De worminfecties plagen vooral de landbouwers, die daardoor veel aan arbeidskracht inboeten; alleen verbetering der sociaaleconomische toestanden onder deze groep, alsmede hygiënische opvoeding, kunnen verbetering brengen.

De malariabestrijding zou de permanente diensten van een speciaal daartoe aangestelden deskundige vereisen, die tot dusver ontbrak.

Gememoreerd wordt, dat in Suriname het eerst de framboesia tropica bestreden werd door salversaninjecties, waardoor deze plaag niet meer een zo ernstige is als vroeger; toch worden er jaarlijks in de districten nog 2000 gevallen behandeld, voor zover dat doenlijk is. Uitroeiüng zou mogelijk zijn, wanneer een voor dit doel aangestelde staf van deskundige werkers beschikbaar ware.

In het algemeen wordt geconstateerd, dat de staat der volksgezondheid in Suriname dragelijk goed is, doch geenszins ideaal, immers labiel. In vergelijking tot andere landen, d.w.z. de zodanige welke voor vergelijking in aanmerking komen, heeft Suriname altijd op dit gebied een goeden naam gehad. Elders echter 
is den laatsten tijd veelgedaan ter verbetering van den toestand en Suriname mag niet achterblijven.

Enkele gegevens betreffende den landbouw verdienen hier gereleveerd te worden. Men schat het vruchtbare laagland, dat gemakkelijk te bebouwen en zonder veel bezwaar te bereiken is, op ongeveer één vierde der gehele oppervlakte van Suriname .... en van dezen bouwgrond is hoogstens één procent in cultuur. Van de bevolking des lands kan circa $60 \%$ geacht worden direct of indirect voor het levensonderhoud van de agrarische activiteit afhankelijk te zijn, ongeveer negentienden van den kleinen landbouw.

De periode welke in het verslag overzien wordt, is die kort vóór en gedurende den oorlog; suiker, koffie en rijst worden de voornaamste uitvoerproducten genoemd voor 1937 en 1938. Dat Suriname per hoofd der bevolking meer koffie uitvoerde dan Brazilië, lijkt weinig te zeggen. Na 1939 kon de suikerproductie niet eens meer in de locale behoefte voorzien, de koffieproductie daalde tot op een tiende; de rijstcultuur ging aanvankelijk achteruit, doch in 1946 was het met rijst beplante areaal groter dan ooit te voren.

Sedert 1930 behoeft, behalve in enkele gevallen van misoogst, geen rijst meer geïmporteerd te worden, is rijst integendeel een exportartikel. Het gebruik van ploegvee door de Aziatische rijstverbouwers heeft de grootte van de per gezin te bewerken oppervlakte sterk doen stijgen.

Van de citruscultuur wordt gezegd, dat tekort aan scheepsgelegenheid den uitvoer belemmerde; wij weten echter dat de export in 1948 al weder een vrij-aanzienlijke hoogte bereikte. In de cocoscultuur wordt wel toekomst gezien.

De eens zo belangrijke cacaocultuur wordt geacht niet uitsluitend ten gevolge van plantenziekten te gronde gegaan te zijn, doch mede door de concurrentie van andere productielanden. Tijdens den oorlog moest soms cacao voor de locale consumptie ingevoerd worden; wij weten dat er thans plannen bestaan om de cultuur weder ter hand te nemen.

Een kleine schets van de tijdens den oorlog aanvaarde landbouwpolitiek toont dat de steun van de overheid vooral verleend zal moeten worden aan den kleinen landbouw. De vooruitzichten van het groot- of plantagebedrijf zijn inderdaad zo weinig hoopvol, in verband met de behoefte aan arbeidskrachten, waarin thans zo moeilijk te voorzien zou zijn, dat stimulering der volkscultures de voor de hand liggende taak lijkt. 
Wat van de veeteelt gezegd wordt opent weinig of geen nieuwe gezichtspunten.

Verder worden nu de onderscheiden bevolkingsgroepen beschreven, in de eerste plaats de Creolen.

Een historisch overzicht behandelt de slavernij en de Bosnegers. Dat ooit de Indianen in Suriname met de kolonisatiemethoden der Spanjaarden kennis gemaakt zouden hebben (bl. 62) is moeilijk te geloven.

Inderdaad zijn de Surinaamse slaven door een zuiver administratieven maatregel tot vrije mensen gepromoveerd en dat er aan de opvoeding der geëmancipeerden tot volwaardige burgers veel ontbroken heeft, kan geredelijk toegegeven worden.

Waarom zou den creool-landbouwer de rijstcultuur niet liggen (bl. 64)? Er werd in Suriname rijst verbouwd, lang voordat de Aziaat er zijn intrede deed. De cacaocultuur op de grondjes in Saramacca was van het plantagebedrijf afgekeken; deze cultuur bloeide in de periode van het ,staatstoezicht" en het lag voor de hand dat de besten der geëmancipeerden er zich op toelegden.

Verbetering van de woningtoestanden wordt noodzakelijk geacht voor de stad, waar de meeste Creolen wonen; thans is hiermede een bescheiden begin gemaakt.

Uit een vergelijkend overzicht van de jaren 1910 en 1945 blijkt dat bij de groep der Creolen het overschot aan vrouwen bestaan gebleven is, zelfs nog iets is toegenomen; bij de Indonesiërs en de Brits Indiërs is het overschot aan mannen in vrij belangrijke mate afgenomen.

De rapporteur hier aan het woord is van mening, dat de Creool, als onderwijskracht, voor zijn Aziatischen mede-inwoner den weg tot de Westerse cultuur gebaand heeft, door welke omstandigheid dan op den duur assimilatie bevorderd zou kunnen worden. Aan den anderen kant wordt gewezen op een meer en meer aan het licht tredende tegenstelling, meer speciaal tussen Creool en $\mathrm{Br}$. Indiër, ook op geestelijk gebied.

Op politiek terrein wordt geconstateerd, dat er ook onder de Creolen vóór 1942 geen partijwezen bestond, doch alleen kiesverenigingen hun candidaten in het vertegenwoordigend lichaam trachtten te brengen.

Van hetgeen er over de taal gezegd wordt (de volkstaal wordt ook hier ,taki-taki” genoemd) is het niet altijd duidelijk of de rapporteur citeert, dan wel eigen gedachten tot uitdrukking brengt. Dat het Neger-Engels ook dea invloed ondergaan heeft van de talen der Aziaten, was niet zo algemeen bekend. 
$\mathrm{Na}$ enige bijzonderheden betreffende de klederdracht der Creoolse vrouwen (uit de volksklasse) besluit het hoofdstuk over de Creolen met een beschouwing over het specifiek Nederlandse karakter van Suriname, dat volgens den schrijver vooral blijkt uit de gelijkheid van taal, godsdienst en levenswijze tussen Creolen en Europese Nederlanders.

Een volgend hoofdstuk is gewijd aan de bevolkingsgroep welke tot dusver angeduid werd als die der Brits Indiërs, doch thans meer algemeen die der Hindostani heet. Inderdaad, waar wij den laatsten tijd vrijwel uitsluitend te doen hebben met afstammelingen van immigranten uit Brits Indië, met Aziaten die in Suriname geboren zijn en Nederlandse onderdanen zijn, is het minder juist den ouden naam te behouden. Een bezwaar is alleen, dat wel het grootste deel bestaat uit aanhangers van het Hindoeïsme, doch er ook een minderheid aanwezig is van Moslims, plus een klein aantal Christenen.

Gewezen wordt op den trek der laatste jaren van Hindostanen van het land naar de stad, waar gelegenheid bestaat om zich te bekwamen tot het uitoefenen van intellectuele beroepen.

Er worden interessante overzichten gegeven van de levensbeschouwingen en de religieuse voorstellingen der onderscheiden sectes onder de Hindoes en de Moslims. Het kastenstelsel onder de eerstgenoemden vertoont zich in Suriname in een zeer milden vorm en van strijd tussen Hindoes en Mohammedanen hoort men weinig of niets.

Ook over de cultuur, de sociale toestanden, het verenigingsleven en de politieke organisatie der Surinaamse Indiërs worden leerzame inlichtingen gegeven.

Hierna geeft het rapport gegevens aangaande de groep der Javanen, thans bij voorkeur Indonesierrs genoemd. Natuurlijk was de Javaan, althans na 1927, reeds bij zijn komst in Suriname Nederlands onderdaan en het is daarom niet mogelijk uit de beschikbare gegevens te berekenen hoe sterk thans het contingent is der in Suriname geborenen van Javaanse herkomst.

Sterk wordt de aandacht gevestigd op de wenselijkheid dat de intellectuele ontwikkeling der bevolkingsgroep in kwestie zich in Europese en meer speciaal in Nederlandse richting zal bewegen, al kan er enige aandacht geschonken worden aan verlangens naar onderwijs in de eigen taal.

Economisch staan de Indonesiërs in Suriname nog achter bij de Aziaten van Britsindische afkomst, hetgeen óók geweten wordt aan de speelzucht der Javanen. 
Hetgeen bekend is aangaande de geringe diepte van het Mohamedanisme bij de Javanen geldt onverminderd ook voor de Indonesiërs in Suriname, wat te begrijpen is, aangezien het niet de cultuurdragers waren, die als contractarbeiders naar Suriname emigreerden. Toch wordt geconstateerd, dat gevoeligheid op het punt van den godsdienst en een sterke geloofsijver, barrières opwerpen tegen de pogingen tot kerstening van de zijde van zending en missie.

Wat het sociale leven betreft wordt er op gewezen, dat de Indonesiër in Suriname weinig contact zoekt met inwoners van anderen landaard, doch veel saamhorigheidsgevoel aan den dag legt ten opzichte van zijn eigen rasgenoten. Politiek begon hij omstreeks 1945 enige belangstelling te tonen.

Met de granmans en kapiteins van de drie voornaamste stammen der Bosnegers hield de Commissie tot bestudering van Staatkundige Hervormingen enige besprekingen. De vertegenwoordigers dezer woudbewoners bleken geen politieke aspiraties te hebben en geen verlangens naar hervormingen welke hun volk zouden raken. Wel maakten de hoofden van de gelegenheid gebruik om klachten en wensen naar voren te brengen op materieel gebied, waarmede natuurlijk de Commissie geen bemoeiïngen had.

Er is ook een woordje gesproken over de medische hulp en over de kwestie der kledij van de hoofden bij contact met de autoriteiten.

De woordvoerders der Indianen (Caraiben en Arowakken) waren wat meer geïnteresseerd; zij meenden dat de oudste inwoners van het land recht hebben op een eigen vertegenwoordiger in de Staten.

Ook zij maakten van de gelegenheid gebruik om niet-politieke verlangens te uiten, als betere medische hulp in het bosland en versterking van het uiterlijke gezag der hoofden.

Wel pijnlijk moet het aangedaan te hebben te vernemen, dat de grote zuigelingensterfte, wegens gebrek aan verloskundige hulp, het voortbestaan van het ras bedreigt.

In tegenstelling tot de Bosnegers klaagden de Indianen ook over het onvoldoende van het onderwijs. Zij verlangen openbare scholen in hun vestigingsplaatsen, met bevoegde leerkrachten; de tegenwoordige onderwijzers der boslandscholen zouden zich meer toeleggen op handel drijven dan op hun eigenlijk taak.

Het verslag neemt de tekst der vragenlij ten op, welke aan een groot aantal personen in Suriname toegezonden zijn, met een toe- 
lichting van de Commissie, nadat vooraf interviews gehouden waren met particulieren en besturen van corporaties. Welke antwoorden binnenkwamen op de vragenlijsten (het waren er ruim 100), zal wel in het tweede deel van het verslag vermeld worden.

Verdere bijlagen bij het Verslag geven overzichten op politiek, fiscaal, financieel en economisch gebied.

Er blijkt dat in 1946 het aantal kiesgerechtigden juist tienmaal zo groot was als in 1866. In 1945 waren 6181 personen aangeslagen in de inkomstenbelasting, waarvan 117 met een inkomen van 10.000 tot 20.000 gulden, 19 met een inkomen van 20.000 tot 40.000 gulden, 7 met een inkomen van 40.000 tot 66.000 gulden, 2 met een inkomen van meer dan 100.000 gulden.

De z.g. begrotingscijfers van 1867 af geven blijkbaar de resultaten (tot en met 1937) der afgesloten rekeningen.

In het Handelsregister waren in 1946 ingeschreven 1343 zaken, waarvan 505 Chinese, 379 zaken van Nederlanders en Ned. onderdanen, 376 van Brits Indiërs.

De in- en uitvoerstaten geven de geldbedragen en de landen van herkomst, resp. van bestemming, van 1933 tot en met 1945 .

Programma's worden opgenomen van vier politieke partijen; er zijn er echter thans al weder meer.

Initiatief-voorstellen blijken er sedert 1900 slechts vijf te zijn ingediend in het vertegenwoordigend college; het betreffende staatje geeft den indruk dat er in de voorafgaande periode (sedert 1868) wat meer zodanige voordrachten behandeld zijn. Opgesomd worden de door de Staten verworpen begrotingen, zijnde drie, in 1872, 1885 en 1936, terwijl die van 1943, als niet op tijd behandeld, door den gouverneur definitief vastgesteld werd.

Het verslag eindigt met enige grafische voorstellingen en landkaartjes.

De vraag is nogal eens opgeworpen, of Suriname (en de Ned. Antillen) rijp zouden zijn voor zelfbestuur en die vraag kon men onlangs beantwoord vinden door een wedervraag, n.l. deze: welk volk is in het algeméén daar rijp voor?

Men zou kunnen zeggen: dàt volk dat zich zelf de autonomie toekent, omdat het er van overtuigd is in staat te zijn, zijn plaats in de wereld der onafhankelijke naties in te nemen. Zó onze voorouders in het laatst der zestiende eeuw, de Angelsaksische 
kolonisten in NoordAmerika in het laatst der achttiende, de ZuidAmerikanen in het begin der negentiende.

Met Suriname (en de Ned. Antillen) staat de zaak toch wel even anders. En het is daarom verheugend dat onze Westindische rijksgenoten blijkbaar rijksgenoten willen blijven, zij het dan met meer interne bewegingsvrijheid dan hun tot dusver toebedeeld was. 